\title{
"Tem gente caminhando pra lá e para cá": caminhar com as crianças - a pesquisa em contexto campesino
}

\author{
"There are back walking back and forth": walking with children - \\ the research in campesino context
}

"Hay gente caminando para allá y para acá": caminar con los niños-
investigación en contexto campesino

Jeruza da Rosa da Rocha*

Marta Nörnberg*

\section{Resumo}

Este artigo discute o caminhar com crianças em contexto campesino como possibilidade metodológica para a pesquisa com crianças. A partir de alguns pressupostos da abordagem etnográfica, as caminhadas com as crianças são descritas como uma ferramenta metodológica capaz de oferecer elementos para interagir com elas em suas dinâmicas sociais. A ação de caminhar com as crianças permite desenvolver uma postura atenta às brechas e às pistas oferecidas por elas sobre a (re)interpretação que fazem da cultura comunitária e da cultura das famílias, em especial, das práticas da pesca e da lida no campo. Os processos interpretativos realizados pelas crianças, em suas relações intergeracionais e intrageracionais, são abordados com base nos conceitos de reprodução interpretativa e cultura de pares. O estudo sustenta metodologias que valorizam a agência das crianças como intérpretes de suas culturas comunitárias e familiares, e como participantes ativas no desenvolvimento e na organização dos processos investigativos. Mostra como o caminhar com as crianças favorece uma maior aproximação às culturas infantis e oferece condições para a escuta sensível de suas vozes.

Palavras-chave: Metodologia de pesquisa. Pesquisa com crianças. Crianças do campo. Cultura de pares. Caminhar com crianças.

Recebido em 10/04/2019 - Aprovado em 15/10/2020

http://dx.doi.org/10.5335/rep.v27i3.12390

Doutora em Educação pela Universidade Federal de Pelotas. Atua no Núcleo Educamemória pela Universidade de Rio Grande (Furg), como pesquisadora colaboradora com estudos envolvendo as infâncias campesinas dos povos e comunidades tradicionais da Serra dos Tapes, RS. Colaboradora do grupo CIC: Crianças, Infâncias, Culturas. Orcid: https://orcid.org/0000-0003-4635-5942. E-mail: luaia.je@gmail.com

** Professora da Universidade Federal de Pelotas (UFPel), Programa de Pós-Graduação em Educação, Faculdade de Educação, Departamento de Ensino. Orcid: https://orcid.org/0000-0002-9865-7056. E-mail: martanornberg0@gmail.com 


\section{Abstract}

This article discusses the walking with children in campesino context as a methodological possibility for the research with children. Based on some ethnographic approach suppositions, the walks with the children are described as a methodological tool able to offer elements to interact with them in their social dynamics. The action of walking with the children enables developing a careful attitude concerning the gaps and clues offered by them about the (re)interpretation they make of the community culture and the culture of the families, especially the practice of fishing and the rural work. The interpretative processes carried out by the children, in their intergenerational relationships and within generations, are approached based on the concepts of interpretative reproduction and the culture of peers. The study supports methodologies which value the acting of the children as interpreters of their community and family cultures, and as active participants in the development and in the organization of the investigative processes. It illustrates how the walking with children favored a greater approach to children's cultures and offered conditions for sensitive listening to their voices.

Keywords: Research methodology. Research with children. Children in the field. Culture of peers. Walking with children.

\section{Resumen}

Este artículo discute el caminar con niños en contexto campesino como posibilidad metodológica para la investigación con niños. A partir de algunos presupuestos del abordaje etnográfico, las caminadas con los niños son descritas como una herramienta metodológica capaz de ofrecer elementos para integrar con ellas en sus dinámicas sociales. La acción de caminar con los niños permite desarrollar una postura atenta a las roturas y las pistas ofrecidas por ellas a cerca de la (re) interpretación que hacen de la cultura comunitaria y de la cultura de las familias, en especial, de las prácticas de la pesca y de la lida del campo. Los procesos interpretativos producidos por los niños, en sus relaciones, intergeracionales y intrageracionales, son abordados con base en los conceptos de reproducción interpretativa y cultura de pares. El estudio sostiene metodologías que valoran la acción de los niños como intérpretes de sus culturas comunitarias y familiares, y como participantes activas en el desarrollo en la organización de los procesos investigativos. Muestra como el caminar con niños favorece un acercamiento a las culturas de los niños y ofrece condiciones para escuchar sus voces con sensibilidad.

Palabras claves: Metodología de investigación. Investigación con los niños. Niños del campo. Cultura de pares. Caminar com niños.

\section{Introdução}

A construção de metodologias de pesquisa que reconheçam as crianças em sua agência, como sujeitos de direitos e participantes dos processos culturais está na agenda do trabalho de investigação educacional. Organizar e desenvolver práticas participativas de interlocução entre adultos e crianças é tarefa necessária para ampliar as relações intergeracionais e as possibilidades de escuta aos processos intrageracionais estabelecidos pelas crianças em suas dinâmicas sociais e comunicativas.

A discussão proposta para este artigo apresenta as caminhadas com crianças que vivem em contexto campesino como ferramenta metodológica. Caminhar no 
campo é atividade cotidiana do grupo de crianças da Capilha, região do Taim, no município de Rio Grande, RS, local onde foi desenvolvida a pesquisa. As caminhadas permitiram a aproximação da pesquisadora com as crianças, além de reconhecer e atentar a outras formas de se movimentarem no cotidiano comunitário e compreender as ressignificações e interpretações da cultura local.

No caso do estudo realizado, o caminhar com as crianças favoreceu a criação de condições para observar como elas interagem entre si e com os adultos, em seu cotidiano comunitário, além de oferecer pistas para pensar sobre a interpretação que fazem sobre a pesca e a lida no campo, atividades típicas da localidade. Além disso, ofereceu insumos para pensar sobre o lugar e a atuação do investigador educacional, especialmente aquelas que referem as modificações de postura, os cuidados éticos a serem estabelecidos e a disponibilidade de reposicionar-se no contexto das práticas culturais vividas pelas crianças como interlocutor capaz de escutar o que e como elas contam suas vivências.

As caminhadas surgiram como movimento próprio das crianças de aproximação à pesquisadora que, em certo momento do seu trabalho de pesquisa na escola, ao final de um dia de aula, foi convidada para com elas caminhar pela comunidade. Assim, com base na experiência da pesquisa realizada, o caminhar com as crianças é apresentado como ferramenta metodológica adequada para a interação entre crianças e pesquisadores, pois cria oportunidades para conversar sobre a sua realidade comunitária e familiar. Além disso, desmistifica o papel do pesquisador como gestor central do processo investigativo, pois, enquanto ação proposta pelas crianças, a caminhada é um convite para aproximar-se de suas realidades infantis, experimentando outras formas de observar e conduzir a pesquisa com crianças, especialmente em contexto campesino.

Os processos interpretativos realizados pelas crianças são discutidos com base nos conceitos de "reprodução interpretativa", de "relações inter e intrageracionais" e de "cultura de pares" (CORSARO, 2009, 2011; SARMENTO, 2005, 2013). Essa base conceitual situa-se no âmbito dos estudos da infância e tem como premissa básica legitimar as crianças como atores sociais ativos e de cultura, potentes em processos de agenciamento nas relações sociais que estabelecem na comunidade pertencente.

As situações ocorridas ou narradas durante as caminhadas são problematizadas e ampliadas com base nos conceitos referidos, especialmente para pensar sobre os vínculos estabelecidos entre sujeitos e, destes, com a sua comunidade e o lugar espacial em que vivem na interlocução que realizam com a pesquisadora. 
Ademais, auxiliam a pensar sobre aspectos relativos à vida na região dos campos neutrais, lugar que carrega simbologias afinadas com um determinado modo de estar no tempo e no espaço geográfico e cultural de um banhado, ambiente típico do Taim, região na qual vivem as crianças participantes da pesquisa. Simbologias que remontam, nas palavras do músico e escritor Vitor Ramil (2011), a um imaginário contemporâneo que abriga ideais de liberdade, diversidade humana e linguística, criatividade, fantasia e realidade.

O conjunto dessas posições teóricas amplia as referências no âmbito da investigação participativa com crianças, pois oferece material para problematizar e desmistificar noções como as de incapacidade de percepção e de expressão de realidades concretas e simbólicas, por vezes ainda atribuídas às crianças. São arranjos conceituais que colocam em evidência a potência das crianças para falar de seus sentimentos, necessidades, interesses e percepções sobre a realidade sociocultural em que estão inseridas. Nesse sentido, as crianças são atores sociais participativos e excelentes comunicadoras da vida no campo, em sua dimensão real e simbólica.

\section{Subsídios dos estudos e da pesquisa com crianças}

Os estudos da infância, ou Childhood Studies, como área de conhecimento e campo de pesquisa, vem se consolidando no cenário investigativo, especialmente propondo a reconceitualização do termo socialização por meio de uma reflexão articulada sobre aspectos históricos, socioeconômicos e demográficos da infância (CORSARO, 2011). São trabalhos que oferecem perspectivas interpretativas para observar e entender as relações geracionais entre crianças e adultos, e o papel que desempenham na sociedade, reconhecendo a sua participação constitutiva para o estabelecimento de um estatuto social da infância.

Desde a Convenção Internacional dos Direitos das Crianças (1989) e do Estatuto da Criança e do Adolescente (1990), a participação das crianças vem ganhando expressividade no âmbito dos estudos acadêmicos e das dinâmicas sociais contemporâneas. No artigo $12^{\mathrm{a}}$, da Convenção, as crianças são reconhecidas como atores sociais de direitos. A liberdade de expressão e a garantia de escuta aos assuntos que as afetam são sinalizadores de sua participação social e de sua condição de cidadãs. Reconhecer as crianças como competentes em suas ações e interpretações proporciona condições para problematização e descentralização da visão moderna, a qual entende a criança como "um sujeito unificado, reificado e essencializado - no 
centro do mundo - que pode ser considerado e tratado à parte dos relacionamentos e do contexto" (DALHBERG; MOSS; PENCE, 2003, p. 63).

No contexto das práticas investigativas e educacionais, é necessário despir-se de conceitos (pré)estabelecidos que norteiam concepções adultocêntricas em relação às crianças que, geralmente, são vistas como sujeitos passivos da cultura que as cercam. A aproximação às teorias sociológicas da infância oferece ao investigador subsídios para observar e compreender a potencialidade da ação coletiva das crianças no processo de produção cultural, seja a que compartilham entre si e com os adultos, em diferentes contextos sociais, ou a que ocorre entre elas, em diversos espaços, como o da comunidade e o da escola em que vivem e atuam. Ainda, esses aportes teóricos oferecem condições e possibilidades para "teorizar o social a partir de um ponto de vista das crianças” (KOSMINSKY, 2010, p. 128).

O conjunto de aspectos aportados pelos estudos da infância ajuda a pensar nas crianças do presente e nas implicações decorrentes da diversidade cultural, social e demográfica que permeiam seus cotidianos. No Brasil, já encontramos uma relevante produção científica atenta a grupos historicamente colocados em lugar de subordinação pelas lógicas classistas, racistas e sexistas, como o das mulheres e das crianças. São estudos marcados por características interpretativas e construcionistas que se interessam pelas especificidades e pela diversidade constitutiva das produções culturais das crianças, lidas como dimensões potentes para os processos de reconhecimento dos seus modos de socialização e de produção das relações entre os grupos geracionais.

No âmbito da produção científica nacional, destaca-se o pioneiro estudo de Florestan Fernandes (2004) que, na década de 1940, apresentou os processos de socialização vivenciados por um grupo de crianças em situações de brincadeiras de um bairro paulistano. Suas observações e análises demonstraram elementos fundamentais às culturas e grupos infantis, contempladas em ações de brincadeiras das crianças aliadas às regras e valores do mundo adulto. Outra estudiosa, Eloisa Rocha (1997), em suas pesquisas, arquiteta o conceito de pedagogia da infância, apresentando os princípios da escuta e das diferenças como constitutivas das relações participativas entre crianças e adultos no contexto escolar. Anete Abramowicz (2011), mais recentemente, sinaliza a inventividade como termo potente a ser colocado no centro das pesquisas que se debruçam sobre a infância. Para a autora, a inventividade permite buscar e produzir movimentos inversos e oportunos para pensar para além de visões adultocêntricas e colonialistas, pois aposta na capacidade e no olhar das crianças sobre a diversidade que as cerca em seus cotidianos. 
Nesse sentido, as posições de Abramowicz reivindicam do pesquisador uma atenção para as condições de existência das crianças brasileiras, observando questões étnicas e de gênero que perpassam suas dinâmicas demográficas.

O reposicionamento das crianças nos últimos vinte anos tem contribuído para consolidar um movimento investigativo com e não para ou sobre as crianças, isto é, "o processo de pesquisa reflete uma preocupação direta em capturar as vozes infantis, suas perspectivas, seus interesses e direitos como cidadãos" (CORSARO, 2011, p. 57). Esse entendimento sustenta os movimentos participativos das crianças como base para a aproximação às suas realidades e como modo para acompanhar as investidas que elas empreendem para reinterpretar o contexto cultural e social a que pertencem.

Assim, com base na Sociologia da Infância de Corsaro (2011), destacamos "reprodução interpretativa", "cultura de pares" e "teia global" como alicerces conceituais que ajudam a problematizar as práticas culturais a partir da interação, da criação e da apropriação interpretativa que as crianças fazem, com seus pares e com os adultos, exibindo os sentidos por elas produzidos. No contexto desta discussão, estes conceitos são entendidos como pontos de referência para pensar o potencial interpretativo e (re)produtivo das crianças e a sua presença em processos investigativos que se preocupam com a diversidade cultural e social que permeia e contribui para a construção de suas infâncias em situações da vida no campo, em que determinadas atividades econômicas estão presentes, bem como valores e condutas típicas do local.

O termo "reprodução interpretativa" transcende a socialização como movimento passivo e linear, oriundo de perspectivas tradicionais, as quais concebem a criança como "alguém apartada da sociedade, que deve ser moldada e guiada por forças externas a fim de se tornar um membro totalmente funcional" (CORSARO, 2011, p. 19). A noção de reprodução interpretativa refere os processos conjuntos e coletivos das crianças, distanciando-se do termo socialização, de vertente individualista, que visa à internalização de conhecimentos e a formação e preparação para o mundo adulto.

A "reprodução interpretativa" abrange perspectivas inovadoras em relação ao processo de socialização: incorpora a participação ativa das crianças na sociedade; sustenta que elas não internalizam passivamente as informações e conhecimentos do mundo adulto; afirma que elas ressignificam, selecionam e apropriam-se dos saberes, produzindo suas próprias culturas de forma inventiva, inovadora e criativa como maneira de lidar com suas necessidades e preocupações (CORSARO, 2011). Em síntese, 
[...] encara a integração das crianças em suas culturas como reprodutiva, em vez de linear. De acordo com essa visão reprodutiva, as crianças não se limitam a imitar ou internalizar o mundo em torno delas. Elas se esforçam para interpretar ou dar sentido a sua cultura e a participarem dela. Na tentativa de atribuir sentido ao mundo adulto, as crianças passam a produzir coletivamente seus próprios mundo e culturas de pares (CORSARO, 2011, p. 36).

Para ampliar o entendimento sobre os processos de socialização e compreender as crianças em sua capacidade de agência recorremos a Sarmento (2005), que explica as culturas da infância como resultantes da convergência desigual de fatores que se localizam em duas instâncias: na primeira estão as relações sociais globalmente consideradas e, na segunda, as relações inter e intrageracionais. Segundo Sarmento (2005, p. 373), a "convergência ocorre na acção concreta de cada criança, nas condições sociais (estruturais e simbólicas) que produzem a possibilidade da sua constituição como sujeito e actor social. Este processo é criativo tanto quanto reprodutivo".

O poder de agência das crianças, deste modo, carrega e articula dimensões provenientes da criação e da reprodução que elas fazem de aspectos estruturais e simbólicos que envolvem suas práticas de socialização e interlocução vividas em seus cotidianos. E é nesse processo que as crianças se colocam como atores sociais e produtores de cultura, devido a sua competência e capacidade "de formularem interpretações da sociedade, dos outros e de si próprios, da natureza, dos pensamentos e dos sentimentos, de o fazerem de modo distinto e de o usarem para lidar com tudo o que as rodeia" (SARMENTO, 2005, p. 373).

Nessa perspectiva, a noção de "reprodução interpretativa" pode ser ampliada a partir da ideia de "teia global", a qual ilustra "características produtivas e reprodutivas", pois representa "um modelo que inclui a reprodução interpretativa como uma espiral em que as crianças produzem e participam de uma série de culturas de pares incorporadas" (CORSARO, 2011, p. 37). As crianças participam e interagem em diversos domínios culturais e sociais em constante transformação. Assim, a teia ou a espiral é tanto produtiva quanto reprodutiva, pois a variação dos domínios e a diversidade dos grupos de pares garantem experiências tecidas coletivamente "sobre os grupos de conhecimentos culturais e instituições aos quais as crianças se integram e que ajudam a constituir" (CORSARO, 2011, p. 39). Nesse sentido, a "teia global" demonstra o conjunto de culturas das quais as crianças participam, reinterpretando informações e conhecimentos de forma criativa e inventiva a partir de suas necessidades de compreender o mundo. 
Chega-se, assim, à discussão sobre “cultura de pares”, que diz respeito à apropriação das crianças "criativamente de informações do mundo adulto para produzir suas próprias culturas" (CORSARO, 2011, p. 53). Não se trata de uma apropriação estática e individual a fim de orientar o comportamento das crianças, mas sim de uma produção que é criativa, pois amplia as "informações do mundo adulto a fim de responder às preocupações de seu mundo" (idem), contribuindo constantemente para a reprodução e a extensão cultural dos adultos.

A atenção neste artigo volta-se para o reconhecimento das crianças em seus movimentos interpretativos sobre as dinâmicas dos grupos geracionais de sua comunidade e com a pesquisadora, com quem elas compartilham criativamente, em exercícios de (re)produção cultural, aspectos de sua participação nas rotinas culturais próprias do contexto campesino em que vivem. Ou melhor, o esforço está em mostrar como seus anúncios interpretativos são potentes para construir uma aproximação com seus cotidianos socioculturais e assim entender os significados que atribuem à sua cultura local. Nessa direção, as caminhadas são entendidas como estratégia que oferece melhores condições para o diálogo entre crianças e a pesquisadora, sobretudo a comunicação das interpretações que realizam sobre as práticas culturais do cotidiano campesino.

Na sequência, a caminhada com as crianças é apresentada como metodologia de pesquisa. Para isso, elementos da abordagem etnográfica da pesquisa com crianças são tomados para explicitar o movimento investigativo desenvolvido. Também aspectos decorrentes das interações ocorridas ao longo das caminhadas são analisados e problematizados com base nos aportes conceituais referidos.

\section{As caminhadas com crianças: 0 que revelam para a pesquisa?}

A pesquisa com crianças é atividade desafiante ao pesquisador. Para desenvolver processos investigativos que colocam como centro as crianças e os seus pontos de vista, é preciso aprender a "examinar, analisar e explicar os mundos que as crianças conhecem porque vivem aí dentro; e ligar as vidas das crianças à organização cotidiana habitual das relações sociais" (KOSMINSKY, 2010, p. 128). Nesse sentido, investir na criação de metodologias que deem visibilidade à "riqueza das vidas das crianças nos inúmeros contextos em que elas se movem" (GRAUE; WALSH, 2003, p. 22) é tarefa do investigador educacional. Assim, a preocupação com as vozes das crianças, as suas perspectivas e seus interesses faz parte da agenda de trabalho de quem procura uma maior aproximação às suas realidades e uma com- 
preensão mais atenta à (re)produção interpretativa que elas fazem das práticas culturais.

Nesta seção o foco recai sobre as caminhadas com as crianças, discutindo-a como possibilidade metodológica na pesquisa. Para argumentar em favor desta ferramenta, elementos da etnografia são tomados para justificar as posições assumidas e os encaminhamentos realizados.

Um primeiro princípio posto pela etnografia demanda ao pesquisador sua participação ativa no cotidiano investigado para assim abrir caminhos para compartilhar das práticas culturais dos atores e acercar-se das interpretações que realizam. É dessa forma que se torna possível uma maior aproximação com os sujeitos e a elaboração de uma compreensão mais razoável e fiel sobre os significados construídos em um determinado contexto sociocultural.

A etnografia se caracteriza como metodologia que prioriza a descrição densa dos fatos e a inserção prolongada do pesquisador no contexto a ser investigado, o que exige o exercício sistemático do registro em diário de campo. Fazer um diário permite registrar o não-dito, as representações simbólicas, o que foi dito fora da entrevista (MELLO, 2005, p. 60). O registro em diário configura-se como uma alternativa potente porque permite, justamente, sistematizar o que resulta da interação entre pesquisador e crianças.

A etnografia com crianças requer do investigador a prática da flexibilização e da renegociação durante o desenvolvimento do processo investigativo. Pede pelo exercício constante de considerar as crianças em suas capacidades de agir como interlocutores centrais, capazes de sinalizar pistas sobre possíveis modos de observar o campo empírico, pois possuem as melhores condições de comunicar sobre os contextos em que vivem. Além disso, desloca a figura do pesquisador do lugar central do processo metodológico de pesquisa. Essa posição demanda, no entanto, que o investigador educacional reconheça a criança potente para "ensinar e comunicar sobre suas experiências de vida compartilhada e suas lutas para obter algum controle sobre os poderosos adultos e suas regras" (CORSARO, 2011, p. 62).

No decorrer da pesquisa, essa capacidade de atenção aos modos das crianças estabelecerem a sua comunicação com o pesquisador sobre sua vida na comunidade da Capilha foi desenvolvida e aprimorada. E, em decorrência desse exercício, é que as caminhadas com as crianças foram assumidas e entendidas como uma ferramenta metodológica capaz de permitir uma maior inserção em contexto e, assim, compreender aspectos do cotidiano real e simbólico por elas interpretados. 
Enquanto proposta metodológica, as caminhadas criaram condições para a observação atenta, pois a pesquisadora, ao ser deslocada do seu lugar de figura central do processo, foi inserida, pelas crianças, como uma participante do grupo e assim foi aprendendo a olhar para as práticas da comunidade, guiada pelas mãos das crianças. Sobre essa dinâmica, Corsaro explica que o pesquisador se acerca melhor das práticas do grupo e, desse modo, "toma a compreensão dos sentidos e da organização social como tema de pesquisa a partir de uma perspectiva de dentro, aprendendo a se tornar um membro do grupo, documentando e refletindo sobre 0 processo" (2009, p. 85).

Mas, como começaram as caminhadas com as crianças?

As aulas daquele dia tinham encerrado; a pesquisadora, sentada na soleira da porta da biblioteca da escola, realizava anotações em seu diário decorrentes das observações feitas naquela manhã em sala de aula. Seu interesse de pesquisa repousava sobre as formas de participação das crianças nas práticas educativas desenvolvidas em uma turma multiseriada. Um grupo de crianças aproxima-se e um convite é feito: "Vamos, nós já almoçamos. Vamos com nós até lá embaixo?". Sem hesitar, coloca-se em pé e segue com as crianças. Ao sair da escola, pergunta: "O que é lá embaixo?". "Ué, é lá embaixo. Olha, tem que subir e depois descer. É lá embaixo que a gente mora". Naquele momento, percebe que a referência "lá embaixo" indicava características do relevo local.

Ao longo da caminhada, as crianças contam sobre como vivem na comunidade da Capilha. Falam de suas brincadeiras. Narram empolgadas sobre histórias com personagens assustadores (lobisomem, noiva sangrenta). Relatam sobre as atividades de pesca e de lida no campo realizadas por suas famílias. Apresentam pessoas e oferecem descrições detalhadas sobre as tarefas que realizam diariamente na comunidade. Mostram a si próprias como pertencentes e envolvidas com práticas típicas dos adultos, como a conversa no balcão do pequeno armazém da localidade.

As caminhadas com as crianças permitiram a construção de outro olhar no desenvolvimento da pesquisa. As situações observadas em sala de aula evidenciavam o comportamento silencioso das crianças, que se manifestavam apenas quando solicitadas pela professora ou quando precisavam manusear materiais entre elas. Em contrapartida, durante as caminhadas pelo pequeno vilarejo, eram espontâneas e tenazes em suas investidas; perspicazes na exposição sobre as situações vividas na escola e na comunidade. Durante o percurso de uma caminhada, argumentavam e interagiam entre si e com a pesquisadora, apresentando um repertório enriquecido 
de informações e conhecimentos sobre suas atividades cotidianas e também dos adultos.

Com as caminhadas, foi possível ampliar a relação de pertencimento à comunidade da Capilha, seja das crianças, como da própria pesquisadora. $\mathrm{O}$ pertencimento ultrapassa o reducionismo biológico porque trata de distinguir a natureza humana na dimensão da vida, mostrando que a noção de pertencimento exige "inscrever a lógica da vida nas condições específicas do modo de organização cultural da sociedade humana" (SÁ, 2005, p. 251). O sentimento de pertencer ultrapassa nascer e viver num determinado lugar porque envolve o gostar das histórias que são contadas sobre o local, a cultura, o dia a dia. Envolve um sentimento de afetividade e de amor pelas coisas e pelos sujeitos da comunidade. Produz, portanto, a compreensão de que os laços extrapolam as dimensões biológicas, pois em razão da cultura, capital genético de segundo grau (MORIN, 2001), outras bases se organizam por meio da linguagem e da comunicação, ampliando as formas de pertencimento, o que inclui dimensões reais e simbólicas, humanas e ambientais.

No decorrer das caminhadas, as crianças relataram sobre os saberes da cultura local e explicaram quais atividades seus familiares mais desenvolviam, entre elas, a pesca e a lida no campo, principais formas de subsistência de suas famílias. As falas das crianças traziam a descrição das tarefas e das posições que ocupavam em situações que envolviam as atividades de trabalho, demonstrando aspectos de sua participação junto aos adultos. Nesses momentos, as produções interpretativas sobre a cultura do lugar foram sendo explicitadas. Expressões como: "eu pesco com o meu pai, agora ele tá matando pouco peixe, o peixe tá mais pro fundo" e "meu pai pesca, eu vou com ele, mas agora ele tá trabalhando de peão" oferecem elementos para demarcar sua participação nas atividades laborais. São falas ilustrativas da leitura que elas fazem da situação econômica em que vivem os moradores e as famílias do local, em referência à condição do tempo cíclico que orienta a sobrevivência e o trabalho na região.

Os relatos das crianças sobre a cultura da pesca e da vida campesina, sobretudo de situações que elas estabeleciam com os adultos são potentes para pensar nas relações geracionais. Em certa ocasião, uma pergunta é feita à pesquisadora: “Tu já comeu bolinho de bochechinha"? Após a resposta indicar desconhecimento, a explicação: “Tu não sabes?! Ué... é um bolinho feito da bochecha do peixe”. Interpelações desta natureza mostram conhecimentos sobre pratos típicos, ao mesmo tempo indicam o estranhamento à pesquisadora e sua capacidade de ressignificação, 
isto é, a interpretação criativa construída pelas crianças em relação às informações que capturam do mundo adulto. É um processo que ultrapassa a imitação, mas a apropriação de informações de forma inventiva, produzindo seus próprios conhecimentos. O relato traz elementos da cultura produzida pelas crianças, a qual, imersa na espiral cultural, definida pelas atividades e saberes da pesca artesanal e da vida campesina, evidenciam a mobilização de seus saberes como grupo geracional pertencente à sociedade, neste caso, à Capilha.

O caminhar com as crianças tornou possível capturar nuances de suas relações com outros adultos da localidade, o que mostrava os conhecimentos delas sobre as práticas sociais cotidianas. Em certo percurso, uma das crianças, que andava de bicicleta, toma distância do grupo que está a pé. Minutos depois, sua bicicleta é avistada em frente a um pequeno comércio. $\mathrm{O}$ grupo interrompe a caminhada e fica à espera do colega que, instantes depois, vem eufórico ao encontro dos colegas dizendo: "Por isso que é bom o cara ser respeitador e conhecer todo mundo. Fui na venda saber quanto custava um chiclete e o J. estava lá. Me disse que eu podia pegar quantos chicletes eu quisesse, mas eu não quis. Aí ele falou: pega, pega, isso é coisa de brother. Então peguei um só”. A fala revela valores que as crianças percebem como brechas, as quais possibilitam suas inserções no grupo dos adultos. Situações como esta mostram aspectos das relações intergeracionais, explicitando a reinterpretação que as crianças fazem quanto aos valores e modos de organização social dos adultos dessa comunidade, em que respeito e conhecimento de todos que ali moram são importantes e são por elas entendidas como estratégias de inclusão, que, então, são recompensadas por seu comportamento.

Entender a cultura das crianças significa reconhecer que elas não produzem de forma isolada as relações que estabelecem com o local e as pessoas que ali vivem. São produções culturais resultantes das interações e das interpretações de informações decorrentes do contato com os adultos, o que as ajudam a construir uma nova leitura do contexto em que vivem. A fala ilustra que elas sabem e reconhecem que o respeito é um modo de estar incluso no grupo dos adultos e de ser aceito como igual, um brother, no caso da comunidade em que vivem.

Em outro momento de caminhada duas crianças se distanciam do grupo e mais à frente agacham-se à margem de um pequeno açude para observar duas tartarugas. Quando o grupo todo se aproxima, uma das crianças que observava os animais conta sobre uma situação vivida com os amigos, no mato, próximo ao açude. "Nesse mato dizem que tem bicho estranho, com asa e cor de tigre. Eu e meus amigos viemos aqui e não achamos nada. Reviramos todo mato”. Em poucos 
instantes, uma exclamação é feita, em tom meditativo: "É... aqui na Capilha tá aparecendo coisas estranhas! Tem gente caminhando, pra lá e pra cá... Aqui era calmo. Agora tá mudando. No verão é que fica pior, vem gente de fora, de carro, acampar com música alta e ficam passando toda hora aqui. Até fazem das árvores de banheiro".

Diante de práticas distintas dos costumes e hábitos locais, as crianças estranham pessoas desconhecidas em seu modo agirem, descrevendo seus comportamentos como contrários ao jeito de viver na Capilha. "Aqui todo mundo se conhece, é bem calmo, só quando vem gente da cidade para descansar que eles ligam o som alto". Elas não estão passivas aos acontecimentos ao seu redor, bem como às informações e conhecimentos que permeiam suas vidas; seus pontos de vista revelam aspectos atentos à imposição cultural, como ouvir música alta, demonstrando sentimentos de desvalorização e desrespeito aos seus modos de ser e estar na Capilha.

O contexto é produto e produtor das vivências das crianças, "é o elo da união entre as categorias analíticas dos acontecimentos macro-sociais e micro-sociais", pois refere um "espaço e um tempo cultural e historicamente situado" (GRAUE; WALSH, 2003, p. 25). O contexto se apresenta como elemento revelador do que constitui o movimento e a dinâmica do cotidiano da Capilha. Nesse sentido, as caminhadas se apresentaram como uma ferramenta capaz de acercar-se das interações sociais e culturais entre as crianças, a comunidade e seus visitantes.

Desse processo algumas aprendizagens para os processos de investigação com crianças podem ser destacadas. Entre elas está a relevância do pesquisador estar atento, de ser um observador sensível ao que se configura ao seu redor. É necessário ser sensível às pistas que o contexto e as crianças oferecem nos momentos de interações ou até mesmo nos momentos de silêncio. Ao realizar as caminhadas, foi possível entender com maior amplitude que os dados "não andam por aí a espera de serem recolhidos" (GRAUE; WALSH, 2003, p. 94), mas decorrem da sensibilidade do pesquisador de percebê-los, especialmente quando se está imerso no campo de investigação e se está disposto à participação, às interações e às relações que são tecidas com os colaboradores da pesquisa.

As caminhadas abriram brechas para que as crianças demonstrassem sua criatividade e capacidade de falar e refletir sobre as dinâmicas e práticas do cotidiano na Capilha. Assim, com as caminhadas o ato de investigar pode ser "[...] concebido como uma série de contextos encaixados uns nos outros, incluindo as perspectivas do pesquisador sobre a investigação, a teoria, e, neste caso, as crianças; o 
papel negociado com/pelos participantes; e as relações que se estabelecem ao longo do tempo" (GRAUE; WALSH, 2003, p. 94). Com base nesse conjunto de elementos articulados é possível compreender as relações produzidas entre crianças e adultos sobre as práticas culturais em sua comunidade.

Durante as caminhadas também foi possível experimentar a construção do respeito e da ética na pesquisa. Um fato ocorrido em um dos momentos de observação na escola, próximo ao término da aula, elucida o respeito e a ética como aspectos necessários à investigação com crianças. Um pequeno grupo de crianças se aproxima e uma fala é dirigida à pesquisadora: "Hoje tá chovendo. Então tu não vais com nós porque estamos de bicicleta!". Acompanhar as crianças durante um dia de chuva atrapalharia seu percurso de retorno até suas casas, pois não permitiria que voltassem com maior rapidez e agilidade.

Diante dos aspectos assinalados, a pesquisa com crianças requer o exercício contínuo de respeitar o espaço e o tempo das crianças e com elas negociar acordos e atividades relativas aos encaminhamentos metodológicos. Fazer pesquisa com crianças significa que, enquanto pesquisadores, necessitamos aprender a compreender e a respeitar suas demandas e necessidades. O caminhar com as crianças, como prática de pesquisa, proporcionou condições para descortinar os mundos infantis vivenciados em contexto campesino e pesqueiro. Ainda, ajudou a compreender as reinterpretações que as crianças realizam sobre a cultura local e o mundo adulto. Como proposta metodológica, as caminhadas permitiram que a geração de dados acontecesse em conjunto com as crianças e, inclusive, contemplasse suas demandas ou seguisse suas sugestões, o que redimensionou o próprio lugar da pesquisadora como gestora central da pesquisa. Desse modo, as caminhadas, como ferramenta de observação e de interação com o universo infantil, ampliam os atos investigativos na medida em que incorporam e inserem as percepções e os significados (re)produzidos pelas crianças sobre o seu pertencimento ao local em que vivem, em suas múltiplas dimensões: social, econômica, cultural.

\section{Algumas pistas para seguir caminhando}

A expressão “Tem gente caminhando pra lá e pra cá” ilustra diferentes pontos de vista e interpretações possíveis para pensar pesquisas que envolvem a participação das crianças. Caminhar pra lá e pra cá com as crianças permite reconhecer e acercar-se de suas formas de mobilidade e interpretação sobre os eventos cotidianos. Para caminhar com as crianças é preciso estar disposto a lançar mão de ações 
que valorizam a sua participação. É necessário querer ouvi-las e respeitá-las em seus tempos de comunicação e de silêncio; sobretudo, é preciso aprender a reconhecer que há outras lógicas por elas mobilizadas para explicar as formas de estar no mundo e de viver em suas comunidades.

"Caminhar pra lá e pra cá" na pesquisa com crianças também requer despir-se de verdades a serem alcançadas e encerradas conceitualmente para assim compreender o que significam atividades como "capturar peixe" e pertencer a um determinado grupo, isto é, ser um "brother", sentidos que estão intimamente relacionados com o lugar em que se atua como agente cultural.

Os sentidos sobre "há gente caminhando pra lá e pra cá", tomando a referência feita aos visitantes e às pessoas desconhecidas à comunidade, conforme relatado pelas crianças, mostram o estranhamento e o enfrentamento entre grupos que se relacionam em determinadas situações, os quais com base em suas diferenças e pertenças culturais atribuem significados e modos de agir distintos, por vezes, divergentes. O posicionamento das crianças, quando questionam tal situação, leva-nos a compreender o seu protagonismo social ao realizarem a leitura do mundo e de seus contextos.

As caminhadas também permitiram observar o protagonismo das crianças por meio de suas falas e conhecimentos sobre as atividades laborais de suas famílias, mostrando-se participativas e sabedoras da cultura a que pertencem. Nesse sentido, as caminhadas possibilitaram experimentar o que na abordagem etnográfica é fundamental, isto é, as significações produzidas pelas crianças "no seu espaço, o espaço numa comunidade alargada" (GRAUE; WALSH, 2003, p. 31).

Os aspectos reunidos apontam as caminhadas como uma ferramenta metodológica que permitiu pensar na "reprodução interpretativa" que as crianças realizam de forma inventiva e criativa, constitutiva de suas próprias teias de culturas e saberes. Teia produzida pelas crianças por meio da participação em locais e domínios institucionais, com seus pares e com os adultos. As relações produzidas por grupos geracionais possibilitam o trânsito de culturas, de saberes e de experiências salientes às culturas infantis, e a sua comunicação e entrecruzamentos são constitutivos das culturas infantis.

A aposta em práticas metodológicas que valorizem abordagens epistêmicas inscritas em campos interdisciplinares, capazes de amparar a realização e a consolidação de pesquisas com crianças, e não sobre ou para, é tarefa necessária aos investigadores do campo educacional. Para isso, é preciso buscar e construir novas ferramentas metodológicas que priorizem as crianças como agentes dos estudos e 
processos investigativos. Nesse sentido, as caminhadas, além de favorecerem uma maior aproximação às culturas infantis, também ofereceram condições para a escuta sensível às suas vozes, na diversidade que as compõem, em suas condições de existência e de (re)produção cultural a partir do cotidiano campesino e pesqueiro em que vivenciam suas experiências infantis.

\section{Referências}

ABRAMOWICZ, A. A pesquisa com crianças em infâncias e a sociologia da infância. In: FARIA, A. L. G. da; FINCO, D. (org.). Sociologia da infância no Brasil. Campinas, SP: Autores Associados, 2011. p. 17-35.

BRASIL. Estatuto da criança e do adolescente: Lei n. 8.069, de 13 de julho de 1990, e legislação correlata [recurso eletrônico]. 9. ed. Brasília: Câmara dos Deputados, Edições Câmara, 2010. 207p. (Série legislação; n. 83). Disponível em: http://www.crianca.mppr.mp.br/arquivos/File/publi/camara/estatuto_crianca_adolescente_9ed.pdf. Acesso em: 16 set. 2018.

BRASIL. Convenção dos Direitos das Crianças, 1990. Decreto no 99.710, de 21 de novembro de 1990. Disponível em:http://www.planalto.gov.br/ccivil_03/decreto/1990-1994/D99710.html. Acesso em: 16 set. 2018.

CORSARO, W. A. Métodos etnográficos no estudo da cultura de pares e das transições iniciais na vida das crianças. In: MÜLLER, F.; CARVALHO, A. M. A. (org.). Teoria e Prática na pesquisa com crianças: diálogos com William Corsaro. São Paulo: Cortez, 2009. p. 83-103.

CORSARO, W. A. Sociologia da infância. Porto Alegre: Artmed, 2011.

DALHBERG, G.; MOSS, P.; PENCE, A. Qualidade na educação da primeira infância: perspectivas pós-modernas. Porto Alegre: Artmed, 2003.

FERNANDES, F. As 'trocinhas' do Bom Retiro: contribuições ao estudo folclórico e sociológico da cultura e dos grupos infantis. Pró-Posições, v. 15, n. 1 (43), jan./abr. 2004.

GRAUE, M. E.; WALSH, D. J. Investigação interpretativa com crianças: teorias, métodos e ética. Lisboa: Fundação Calouste Guibenkian, 2003.

KOSMINSKY, E. V. Pesquisas com crianças e jovens: algumas reflexões teórico-metodológicas. In: MULLER, F. (org.). Infância em perspectiva: políticas, pesquisas e instituições. São Paulo: Cortez, 2010.

MELLO, M. A. L. Pesquisa Participante e Educação Popular: da Intenção ao gesto. Porto Alegre: Ed. Ísis; Diálogo-Pesquisa e Assessoria em Educação popular; IPPOA - Instituto Popular Porto Alegre, 2005.

MORIN, E. O Método 2. A vida da vida. Porto Alegre: Sulina, 2001.

RAMIL, V. A linha fria do horizonte. 2011. Linha Fria Filmes. Documentário. DVD.

ROCHA, E. A. C. Infância e pedagogia: dimensões de uma intrincada relação. Perspectiva, Florianópolis, v. 15, n. 28, p. 21-33, jul./dez. 1997. 
SÁ, L. M. Pertencimento. In: JÚNIOR, L. A. F. Encontros e caminhos: formação de educadoras(es) ambientais e coletivos educadores. Brasília, DF: MMA, Diretoria de Educação Ambiental, 2005. p. 245-255.

SARMENTO, M. J. A Sociologia da infância e a sociedade contemporânea: desafios conceituais e praxeológicos. In: TEODORA, R.; GARANHANI, M. C. (org.). A sociologia da infância e a formação de professores. Curitiba: Champagnat, 2013. p. 13-46.

SARMENTO, M. J. Gerações e alteridade: interrogações a partir da sociologia da infância. Educação \& Sociedade, Campinas, v. 26, n. 91, p. 361-378, maio/ago. 2005. 